\title{
O PROGRAMA REDEFOR EDUCAÇÃO ESPECIAL E INCLUSIVA: UMA EXPERIÊNCIA DE FORMAÇÃO EM SERVIÇO DE PROFESSORES E GESTORES NA MODALIDADE SEMIPRESENCIAL
}

\author{
Paula Mesquita Melques, Elisa Tomoe Moriya Schlünzen \\ Universidade Estadual Paulista - UNESP, Programa de Pós-graduação em Educação, Presidente Prudente, SP. E-mail: \\ paulamelques@gmail.com
}

\section{RESUMO}

O presente trabalho tem como objetivo apresentar uma experiência de formação em serviço de professores e gestores da rede estadual de ensino de São Paulo. Trata-se do programa Rede São Paulo de Formação Docente (Redefor) Educação Especial e Inclusiva, oferecido na modalidade semipresencial, a partir da parceria entre Secretaria Estadual da Educação de São Paulo, Escola de Formação e Aperfeiçoamento dos Professores, Pró-Reitoria de Pós-Graduação e Núcleo de Educação a Distância da Universidade Estadual Paulista. Após a realização dos sete cursos de especialização, pautados nas abordagens Estar Junto Virtual (EJV) e Construcionista, Contextualizada e Significativa (CCS), observou-se índice de cerca de $80 \%$ de aprovação e impactos positivos no ambiente escolar, como o aperfeiçoamento da prática de docentes e gestores que podem atuar como multiplicadores no seu contexto de atuação e contribuir com a construção de uma escola mais inclusiva.

Palavras-chave: Programa Redefor, Educação Especial e Inclusiva, Formação em serviço, Educação a Distância, Formação de professores.

\section{THE PROGRAM REDEFOR SPECIAL AND INCLUSIVE EDUCATION: A TEACHER AND MANAGERS IN SERVICE TRAINING EXPERIENCE OF THE STATE OF SÃO PAULO TEACHING IN A HYBRID EDUCATION}

\begin{abstract}
This study aims to present a teacher and managers in service training experience of the state of São Paulo teaching. This is the Program Rede São Paulo de Formação Docente (Redefor) Special and Inclusive Education, offered in a hybrid education in partnership with Education Department of São Paulo (SEE-SP), Training and Improvement Magistrates School (EFAP), Unesp Postgraduate Pro Rectory and Distance Education Center of São Paulo State University (NEaD/UNESP). After the completion of the seven specialized courses, lined the approaches Estar Junto Virtual (EJV) and Construcionista, Contextualizada e Significativa (CCS), observed rate of about $80 \%$ approval and positive impact on the school environment, such as the improvement of the practices of teachers and managers who can act as multipliers in the context of work and contribute to construction of an inclusive school.
\end{abstract}

Keywords: Program Redefor, Especial and Inclusive Education, Service training, Hybrid Education, Teacher training. 


\section{INTRODUÇÃO}

O programa Rede São Paulo de Formação Docente - Redefor - foi uma iniciativa da Secretaria de Educação do Estado de São Paulo (SEE-SP), desenvolvida por meio de convênios com a Universidade de São Paulo (Usp), Universidade Estadual de Campinas (Unicamp) e Universidade Estadual Paulista "Júlio de Mesquita Filho" (Unesp), sendo as universidades responsáveis pela promoção dos cursos de formação continuada - cursos de especialização a nível de pós-graduação lato sensu na modalidade semipresencial.

Com o programa, buscou-se, a partir da formação em serviço, atender a demanda da rede estadual de ensino e, com isso, esperou-se ter impactos positivos na aprendizagem dos estudantes. Para isso, o conteúdo dos cursos foi acompanhado por especialistas da SEE-SP.

De acordo com dados da SEE-SP ${ }^{1}$, mais de 10 mil profissionais obtiveram acesso à especialização universitária por meio do programa Redefor em sua primeira e segunda edição, entre os anos de 2012 e 2013.

Entre os cursos ofertados, estão os que pertencem ao Programa Redefor Educação Especial e Inclusiva, ofertado a partir da parceria entre a SEE-SP, a Escola de Formação de Professores (Efap), a Pró-reitoria de pós-graduação (Propg) da Unesp e o Núcleo de Educação a Distância da Unesp. Para o oferecimento de tais cursos, foi realizado um levantamento inicial pela SEE-SP no estado de São Paulo a fim de identificar a demanda por cursos nessa área. Na ocasião, houve aproximadamente 17 mil professores e gestores interessados.

O programa Redefor Educação Especial e Inclusiva teve como objetivo aperfeiçoar a formação de professores da sala comum e do serviço de apoio pedagógico especializado (SAPE), assim como dos gestores da rede pública estadual de ensino para a escolarização dos estudantes público alvo da Educação Especial (EPAEE) com qualidade e difundir o conceito de educação especial na perspectiva da educação inclusiva. Nesse sentido, esperou-se que os profissionais atuassem em seus contextos educacionais como articuladores no processo de inclusão escolar promovendo o desenvolvimento dos EPAEE, conhecendo, planejando e avaliando práticas pedagógicas, além de planejar ações colaborativas com foco em um projeto pedagógico (PPP) inclusivo.

Com início em 2014 e já concluídos, foram ofertados 7 (sete) cursos de especialização, sendo 6 (seis) nas áreas da Educação Especial - Deficiência Visual (DV), Deficiência Auditiva/Surdez (DA/S), Deficiência Física (DF), Deficiência Intelectual (DI), Altas Habilidades/Superdotação (AH/S) e Transtorno Global do Desenvolvimento (TGD) - e um curso de Educação Especial na Perspectiva da Educação Inclusiva, totalizando 1.600 vagas.

A concepção e o desenvolvimento dos cursos estiveram pautados nas abordagens Construcionista, Contextualizada e Significativa (CCS) (SCHLÜNZEN, 2005) e Estar Junto Virtual (VALENTE, 1999). A abordagem CCS permite que o estudante construa algo que faz parte do seu contexto e vivência por meio do uso das Tecnologias Digitais de Informação e Comunicação (TDIC), despertando assim o seu interesse e permitindo que ele, com a mediação do professor, explore, pesquise, descreva, reflita e depure as suas ideias em um processo espiral de aprendizagem (SCHLÜNZEN, 2005; 2015). Já a abordagem Estar Junto Virtual, de acordo com Valente (1999), implica em mudanças no modelo tradicional de ensino para a EaD. Nela, é necessário criar condições para que o professor esteja junto ao estudante, entendendo o que ele faz, propondo novos desafios e auxiliando-o a atribuir significado ao que está realizando.

Concluída a apresentação geral do programa Redefor Educação Especial e Inclusiva, o objetivo do presente artigo é apresentar a estrutura e os resultados dos cursos ofertados.

\footnotetext{
${ }^{1}$ Disponível em <http://www.educacao.sp.gov.br/redefor>. Acesso em 14 jul. 2016.
} 


\section{METODOLOGIA}

Este trabalho está vinculado ao Programa Redefor Educação Especial e Inclusiva e à pesquisa intitulada "Rede de educação inclusiva: Formação de Professores nos âmbitos de Pesquisa, Ensino e Extensão", aprovada pelo Comitê de Ética em Pesquisa (CAAE), da Faculdade de Ciências e Tecnologia (FCT), UNESP, campus de Presidente Prudente, SP, sob o no 26341614.3.0000.5402, cujo parecer no 173.558 é datado de 07 de dezembro de 2012.

Os cursos nas áreas da Educação Especial, com duração de 686 horas, tiveram como objetivo formar professores e gestores para atuarem no SAPE. Cada um desses cursos teve inicialmente 100 vagas, mas devido à procura ter sido maior em determinados cursos, por solicitação da SEE-SP, houve remanejamento das vagas, mantendo o total de 600 vagas oferecidas.

O curso de Educação Especial na Perspectiva da Educação Inclusiva, com duração de 444 horas e 1.000 vagas, teve como objetivo formar professores e gestores para aprimorarem o repertório de conhecimentos e saberes sobre o tema, atuando no desenvolvimento dos EPAEE a fim de promover uma educação inclusiva.

Tais cursos ocorreram na modalidade semipresencial, com atividades on-line realizadas em um Ambiente Virtual de Aprendizagem (AVA) Moodle e encontros e provas presenciais realizados nas Diretorias de Ensino do estado de São Paulo. Além das atividades citadas, também foi desenvolvido (com orientações virtuais) e apresentado (presencialmente) o Trabalho de Conclusão de Curso (TCC).

A estrutura do curso foi composta por diversos profissionais que seguiram determinado fluxo de trabalho, fundamental para o bom desenvolvimento do trabalho em equipe.

Parceiras no convênio, na figura da Unesp, há a Propg, e representando a SEE-SP, a Efap. Todos os cursos do Programa Redefor Educação Especial e Inclusiva foram coordenados pela coordenação acadêmica - além do apoio da coordenação geral e da coordenação de mídias do NEaD/Unesp.

Por sua vez, a coordenação acadêmica contava com o apoio das coordenações de área e de especialistas. Entre as funções do especialista, estavam acompanhar a produção das disciplinas pelos professores autores e o trabalho da equipe multidisciplinar nesse processo, e também orientar e supervisionar a atuação dos tutores on-line.

Os denominados professores autores são os conhecidos frequentemente como professores conteudistas, autores dos conteúdos das disciplinas (materiais, atividades e provas). Em sua maioria, pertencem ao quadro de docentes doutores da Unesp.

Cada tutor on-line atuou em uma turma de aproximadamente 35 cursistas, sendo responsável por acompanhá-los durante todo o curso no desenvolvimento das atividades virtuais, com o papel de orientá-los, solucionar as dúvidas, atribuir feedback e nota às atividades, tendo como parâmetro a abordagem Estar Junto Virtual (VALENTE, 1999). Para desempenhar as suas atividades, os tutores on-line cumpriam $30 \mathrm{~h}$ semanais presenciais no polo, sob supervisão e orientação da coordenadora de área e dos especialistas. Esses profissionais, os tutores on-line, foram contratados em regime CLT (Consolidação das Leis do Trabalho), por meio de processo seletivo público, com prova de títulos - abrangendo a formação acadêmica e a experiência profissional, com pontuações que valorizavam conhecimentos em áreas como educação, Educação Especial, EaD e atuação como tutor -, e prova prática on-line, realizada no AVA Moodle, com situações problemas a fim de identificar os candidatos com perfil compatível com a atuação desse profissional.

Os tutores presenciais foram selecionados pela SEE-SP e atuavam na rede estadual de ensino como professores e/ou gestores. Esses profissionais tinham como atribuição participar dos encontros presenciais realizados nas diretorias de ensino de SP, executando e mediando as atividades propostas previamente pelos professores autores, especialistas dos cursos e coordenações de área. Nos encontros presenciais, os cursistas eram alocados de acordo com a sua 
diretoria de ensino de origem e não por curso. Assim, participavam do desenvolvimento das atividades cursistas das diferentes áreas da Educação Especial e Inclusiva, o que pedagogicamente implicava em compartilhamento de experiências e saberes, assim como permitia que as atividades fossem propostas de maneira a promover a articulação entre os diferentes profissionais e áreas, como também deve ocorrer na escola.

Ao final das disciplinas, no período de realização do TCC, foram contratados professores orientadores que ficaram responsáveis por 10 a 20 cursistas. A orientação dos TCC ocorreu em salas específicas, organizadas por curso, no AVA Moodle.

A equipe multidisciplinar, pertencente ao NEaD/Unesp, contemplava diversos profissionais, entre eles:

$>$ grupo de Tecnologia da Informação, responsável por garantir a infraestrutura necessária para o desenvolvimento dos cursos a distância;

$>$ assistente técnico em redação, atuando na revisão dos materiais quanto às normas ortográficas e gramaticais da Língua Portuguesa, na adequação da normatização e na publicação de materiais no Acervo Digital da Unesp²;

$>$ designer gráfico, responsável pela criação de identidade visual do curso e pelos aspectos gráficos dos materiais produzidos, como a diagramação dos textos elaborados em formato PDF, ou ainda, pela implementação de textos em formato HTML;

$>$ equipe de produção audiovisual, atuando na gravação e edição de vídeos, como também dando suporte a outros tipos de materiais audiovisuais (animações, por exemplo);

$>$ secretaria acadêmica, prestando assistência administrativa aos cursistas e membros da equipe;

$>$ consultores em acessibilidade, responsável por garantir e otimizar o acesso de pessoas com deficiência aos portais do curso (como o Portal Edutec ${ }^{3}$ ) e AVA Moodle a partir de orientações à equipe multidisciplinar e validações de todos os espaços virtuais do curso;

$>$ audiodescritor, responsável por realizar a tradução das imagens em palavras de maneira que o cursista com deficiência visual conseguisse ter acesso ao conteúdo imagético por meio do leitor de tela, no caso de texto, ou por voz, no caso de vídeos, por exemplo;

$>$ intérprete de Libras (Língua Brasileira de Sinais), profissional que trabalhou com os recursos audiovisuais, realizando a tradução e interpretação do áudio em Língua Portuguesa para Libras e também na elaboração de legendas;

> webdesigner, responsável pela implementação e configuração das disciplinas no AVA Moodle;

> designer educacional (DE), profissional que atuou na mediação entre a equipe multidisciplinar e os professores autores e acompanhou a produção de todos os materiais e conteúdos pedagógicos, fazendo com que cada material seguisse o fluxo estabelecido. Assim, o DE atuou, de maneira colaborativa, desde a elaboração do cronograma e definição dos objetivos da disciplina junto aos professores autores, elaboração das propostas de atividades e materiais, até a validação do ambiente da disciplina.

Assim, os profissionais da equipe multidisciplinar e os demais envolvidos na concepção, produção e realização dos cursos atuaram de maneira articulada e colaborativa a fim de atender aos pressupostos das abordagens CCS e EJV e, com isso, obter resultados satisfatórios no desempenho dos cursistas, assim como no contexto escolar em que atuam.

\footnotetext{
${ }^{2}$ Disponível em: http://www.acervodigital.unesp.br/. Acesso em: 15 mai. 2016.

${ }^{3}$ Disponível em: http://edutec.unesp.br/. Acesso em: 15 mai. 2016.
} 


\section{RESULTADOS}

A realização do Programa Redefor Educação Especial e Inclusiva possibilitou resultados significativos para a Universidade, para a SEE-SP e, em especial, para os cursistas e seus contextos escolares.

Em relação a SEE-SP e aos cursistas - professores e gestores da rede estadual de ensino -, houve aperfeiçoamento profissional do público-alvo, que tem a possibilidade de atuar como multiplicador em seu contexto de atuação, tornando os ambientes escolares mais inclusivos; impacto na aprendizagem dos estudantes e no processo de inclusão escolar da rede pública estadual a partir da formação em serviço; novas possibilidades de atuação, como no atendimento pedagógico especializado, no caso dos cursos de Educação Especial; geração de documentos reflexivos por meio de atividades como o Trabalho de Conclusão de Curso; compartilhamento e socialização de práticas pedagógicas para a rede como um todo; entre outros resultados.

Os resultados também podem ser observados no âmbito da Universidade como, por exemplo, com a possibilidade de desenvolver cursos que articulassem a teoria e a prática considerando o contexto dos cursistas e as necessidades levantadas por eles no âmbito escolar, considerando a função que cada um desempenhava no sistema estadual de ensino; produção intelectual sobre educação especial nas diversas áreas e educação inclusiva; aquisição de infraestrutura e knowhow para produção e oferta de cursos na modalidade de EaD; e também, expansão da oferta de materiais didáticos-pedagógicos em acervo digital público da universidade.

Também é possível observar as contribuições das abordagens CCS e EJV a partir de publicações no AVA realizadas pelos cursistas. No primeiro depoimento apresentado, a cursista demonstra a importância do propósito da atividade e o seu interesse em realizá-la ao construir algo que fazia parte do seu contexto.

[...] A minha alternativa em meu espaço de trabalho e pela falta dos recursos de TA, seria confeccionar alguns materiais para que os nossos alunos pudessem utilizar de forma prazerosa [...]. Do curso todo, a parte mais prazerosa para mim é o estagio, porque utilizamos o que aprendemos na teoria voltada para a nossa prática, tenho aprendido a cada instante, muitas vezes estamos com o material nas mãos e não temos a criatividade de elaborar situações desafiadoras de aprendizagem para os nossos alunos público alvo da Educação Especial. Nesta atividade aprendi muito, porque conhecia do aluno da escola e nos A.T.P.Cs, a professora sempre levava o caso para o coletivo e como sempre todos ouviam e ninguém manifestava ajuda. Então me coloquei a disposição para ajudá-la, expliquei a atividade para a professora e elaboramos juntas as atividades com o material dourado. Acredito que não foi apenas uma atividade para se cumprir uma comanda e sim uma atividade que precisa estar sempre voltada para a aprendizagem de todos os alunos. Eu e a professora da sala pudemos perceber que o aluno Guilherme já tinha um conhecimento sobre unidades e dezenas que a professora da sala não havia percebido. Aspecto este que precisará ser revisto com o auxilio da coordenação para o sucesso da aprendizagem do Guilherme propiciando situações desafiadoras para ele em seu dia a dia [...] (Cursista, informação pessoal).

Outra cursista apresenta a sua satisfação ao colocar em prática o que aprende no curso e observar os resultados. Além disso, enfatiza a papel da mediação do tutor on-line nesse processo, ao valorizar o que a cursista sabe, entendê-la e propor novos desafios, auxiliando-a no seu processo de aprendizagem. 
[...] Estou conseguindo aprender, várias das atividades propostas aqui faço aplicações reais e vejo o resultado. Não posso deixar de te agradecer por ser atenciosa comigo, me corrigir, compreender quando estou irritada, e ainda assim respeitar a minha maneira de ser e de pensar. Nas correções você valoriza as minhas ideias, me incentiva e pede para refazer toda vez que percebe que sou capaz de fazer melhor. Confesso que às vezes fico irritada, pois com tantos afazeres no dia a dia refazer uma atividade é algo massante, porém quando vejo o resultado final, sua avaliação, eu penso: "Valeu a pena, tive a oportunidade de aprender mais um pouco" [...] (Cursista, informação pessoal).

Em relação aos resultados quantitativos alcançados, 1268 (79,3\%) cursistas foram aprovados, 271 (16,95\%) foram reprovados por nota, por frequência ou por nota e frequência, e 60 (3,75\%) desistiram do curso, totalizando 1599 cursistas participantes do Programa Redefor Educação Especial e Inclusiva.

\section{DISCUSSÃO}

A modalidade de EaD possui suas particularidades e é preciso considerá-las desde o processo de produção do curso a fim de obter resultados satisfatórios na formação dos cursistas e no contexto de atuação deles. Frequentemente ocorre a transposição de metodologias de ensino tradicionais para a modalidade a distância, resultando na virtualização da sala de aula, impedindo que as potencialidades do AVA sejam usufruídas e colocando o foco no ensino e na transmissão de informações.

Nesse sentido, acredita-se que a utilização das abordagens pedagógicas CCS e EJV tenha contribuído para que os cursistas se sentissem motivados diante de propostas que consideraram o contexto escolar e que permitiram que construíssem algo de interesse deles, como instrumentos de avaliação, planejamentos de ensino e recursos de Tecnologia Assistiva. Com isso, os cursistas puderam se sentir desafiados e acompanhados constantemente pelos seus tutores, o que resultou em alto índice de aprovação e baixa taxa de evasão, considerando-se principalmente que na $\mathrm{EaD} a$ desistência frequentemente é ainda maior do que no ensino presencial.

\section{CONCLUSÃO}

Com a oferta dos sete cursos de especialização em Educação Especial e Inclusiva, esperouse oportunizar que professores e gestores se aperfeiçoassem para a atuação no contexto escolar como articulares no processo de inclusão, promovendo o desenvolvimento dos EPAEE a partir de práticas pedagógicas e ações colaborativas com foco em um PPP inclusivo.

Os seis cursos na área da Educação Especial possibilitaram formar professores especializados nas áreas das deficiências, TGD e AH/SD para atuar no serviço de Apoio Pedagógico Especializado (SAPE), uma demanda do estado de SP, e também, para que atuem colaborativamente com os gestores e professores da sala comum de maneira que o EPAEE tenha a oportunidade de se desenvolver no ambiente escolar como os demais estudantes.

O curso de Educação Especial na perspectiva da Educação Inclusiva permitiu que professores da sala comum e gestores tivessem formação em serviço e aperfeiçoassem as suas práticas no contexto escolar considerando as especificidades dos seus estudantes.

Nesse sentido, o compartilhamento de experiências e saberes e a articulação entre os diferentes agentes escolares é fundamental para que seja possível adotar práticas inclusivas a fim de atender não só os EPAEE, como todos os estudantes, considerando a diversidade presente nas escolas. 
Por fim, ressalta-se que identificar como as abordagens CCS e EJV podem ser incorporadas à dinâmica do curso e quais são os impactos do curso na prática dos cursistas, tendo como objeto de estudo o programa Redefor Educação Especial e Inclusiva, é um dos objetivos da tese de doutorado em processo de desenvolvimento a ser defendida pela autora.

\section{REFERÊNCIAS}

VALENTE, J. A. Diferentes Abordagens de Educação a Distância. Artigo Coleção Série Informática na Educação - TVE Educativa, 1999.

SCHLÜNZEN, E. T. M. A Tecnologia para inclusão de Pessoas com Necessidades Especiais (PNE). In: PELLANDA, N. M.; SCHLÜNZEN, E. T. M.; SCHLÜNZEN JUNIOR, K.. (Org.). Inclusão Digital: Tecendo Redes Afetivas/Cognitivas. 1ed. Rio de Janeiro: DP\&A, 2005, v. 1, p. 195-210.

Abordagem construcionista, contextualizada e significativa: formação, extensão e pesquisa em uma perspectiva inclusiva. Tese de Livre Docência. Faculdade de Ciências e Tecnologia, Universidade Estadual Júlio de Mesquita Filho, Faculdade de Ciências e Tecnologia, Presidente Prudente, 2015. 